\title{
Aluno Surdo na Ciência da Computação: Discutindo os Desafios da Inclusão
}

\author{
Clodis Boscarioli, Guilherme Galante, Marcio Seiji Oyamada, Reginaldo A. Zara, \\ Rosangela Villwock
}

Colegiado de Ciência da Computação - Universidade Estadual do Oeste do Paraná (UNIOESTE) - campus de Cascavel - CEP: 85819-110 - Cascavel - PR - Brasil

\{clodis.boscarioli, guilherme.galante, marcio.oyamada, reginaldo.zara, rosangela.villwock\} @unioeste.br

\begin{abstract}
This work presents some challenges for inclusion of deaf students in Computer education resulting from the trajectory observation of an academic enrolled in a Computer Science course. The challenges and actions do not intend to support a comprehensive theory or statistics, but raise a reflective discussion considering the particularities of deaf education. Due increasing number of students with this disability entering in the university these challenges must be known to adapt it to this scenario.
\end{abstract}

Resumo. Este trabalho relata desafios encontrados na inclusão de alunos surdos no ensino da Computação e resultam da observação da trajetória de um acadêmico matriculado no Curso de Ciência da Computação. Os desafios apresentados e as ações desencadeadas não têm por objetivo fundamentar uma teoria abrangente ou mesmo estatística, mas sim suscitar discussão reflexiva frente às suas especificidades. Dado o aumento do número de alunos com essa deficiência no ensino superior, é importante que esses desafios estejam claros para que as universidades possam se adequar a esta realidade.

\section{Introdução}

Dados divulgados pelo Ministério da Educação apresentam um aumento significativo de estudantes com deficiência no ensino superior no Brasil, com crescimento de $993 \%$ entre 2000 até 2010. Segundo dados do MEC/INEP do censo de 2011, 8.961.724 alunos se matricularam no ensino superior brasileiro. Destes, $29.033(0,32 \%)$ possuíam algum tipo de necessidade educacional especial, sendo 5.065 (17,44\% do total) com deficiência auditiva, 2.067 (7,11\%) surdos e 211 (0,72\%) com surdo-cegueira [DAROQUE, 2011].

Segundo Bisol et al. (2010), a crescente presença de estudantes surdos em contextos universitários ainda é recente, e decorre de diversos fatores, entre os quais: o reconhecimento oficial no ano de 2002 do status de língua para a Língua Brasileira de Sinais (Libras); e o momento histórico no qual políticas públicas de inclusão vêm aos poucos aumentando o acesso e a participação ativa de pessoas com necessidades especiais em diferentes contextos sociais. Contudo, a inclusão apropriada desses alunos no ensino superior ainda impõe uma série de desafios não apenas aos educadores e estudantes, mas também, de forma mais geral, às Instituições de Ensino Superior.

A pesquisa em educação de surdos tem aumentado nos últimos anos. Em um levantamento sobre a produção acadêmica a partir do Banco de Teses e Dissertações da Capes para o período de 2007 a 2011, Pagnez e Sofiato (2014) mostram que, embora a produção esteja concentrada nas áreas de Educação e Linguística, a área de Ciência da 
Computação exibe contribuição significativa e contínua. A contribuição da Ciência da Computação também é destacada por Ramos e Zaniolo (2014), que buscaram no Banco de Teses da CAPES pelo assunto Educação de surdos para os anos base 2005 a 2009. Em ambos os estudos os autores ressaltam a produção na área de Computação e Tecnologias. Essa contribuição para a temática de Educação dos surdos pode induzir o interesse de estudantes surdos em optar pelo ingresso nesta área no Ensino Superior.

Este artigo discute a inserção de um aluno surdo no Curso de Bacharelado em Ciência da Computação na Universidade Estadual do Oeste do Paraná (Unioeste), no campus de Cascavel, a partir do ano letivo de 2013, com ênfase nas adequações necessárias e nos limites encontrados à inclusão, e nas lições aprendidas, e segue assim organizado: A Seção 2 traz os trabalhos relacionados e os desafios da inclusão do aluno surdo no ensino superior. A Seção 3 descreve as experiências e relato dos professores que atuaram com o aluno. E, na Seção 4, conclusões e perspectivas são apresentadas.

\section{Educação de Surdos - Trabalhos Correlatos}

Segundo Fernandes (2008), em 90\% dos casos, os indivíduos surdos nasceram e estão inseridos em um ambiente familiar de não surdos, o que inviabiliza a apropriação do português, limitando-os a sistemas gestuais que são aprendidos por estímulos visuais durante sua infância. $\mathrm{O}$ grande percalço presente na comunicação entre o português e a Libras é a grande diferença estrutural entre as línguas. Quadros e Karnopp (1997) apresentam a estrutura da Libras com seus aspectos fonológicos, morfológicos e sintáticos próprios, como instrumento linguístico visual-espacial.

O indivíduo surdo, portanto, está inserido em um ambiente no qual tem seu processo de ensino-aprendizagem prejudicado pela ausência de uma metodologia adequada nas escolas, o que impactará no seu ingresso e permanência no ensino superior. Isto se deve à limitação das informações que provém de estímulos sonoros, o qual produz lacunas de aprendizagem, que por sua vez devem ser supridas por outras fontes, principalmente visuais, como imagens, animações, vídeos, textos, jogos, ou seja, qualquer artefato que transmita as informações a este público-alvo, principalmente vi' (Tradutor e Intérprete da Língua de Sinais). De acordo com [LEITE, 2004; QUADROS, 2004], o TILS que atua no ambiente educacional tem como função a interlocução entre o professor e o aluno surdo, interpretando a língua portuguesa para a Libras enquanto o professor mantém sua função de ensinar.

O vocabulário da Libras ainda é insuficiente para expressar todos os conceitos científicos [BOTAN, 2008; SILVA, 2013]. Ainda há a possibilidade de estes possuírem significações divergentes ou ambíguas em relação ao sentido técnico-científico. Uma vez que o TILS, por não ter formação na área, pode não reconhecer diferenças entre os sentidos assumidos pelos sinais de Libras daqueles assumidos pelos termos científicos expressos em língua portuguesa pode levar a uma compreensão inadequada pelo aluno surdo. Considerando que grande parte dos professores também não é fluente em Libras estes desconhecem, portanto, as divergências e dubiedades dos sinais em relação à língua portuguesa. É interessante observar que essa limitação também ocorre em outras línguas, como mostra o trabalho de Andrei et al. (2013), no qual os autores propõem um conjunto de sinais relacionados aos conceitos da computação para a Língua Americana de Sinais e apresentam um software de tradução automática.

No Brasil alguns trabalhos apresentam a experiência de alunos surdos no ensino superior. Cruz e Dias (2009) apresentam um relato com sete estudantes surdos, onde foi 
detectado que a maior dificuldade é em disciplinas com conteúdo mais abstrato e vocabulário específico, como filosofia e sociologia. Em Daroque (2011), um estudo realizado com quatro alunos surdos e seis professores mostra que a dificuldade de leitura e escrita em razão da baixa qualidade do ensino básico e médio é um impeditivo à inclusão efetiva desses alunos no ensino superior, e propõe a criação de uma disciplina de língua portuguesa voltada para surdos para que tais dificuldades sejam superadas. Também para Moreira e Fernandes (2009) um elemento a ser superado é a organização didático-pedagógica dos currículos voltada para alunos ouvintes. Desta forma, a inclusão do aluno surdo no ensino superior ocorrerá apenas com a organização de conteúdo e práticas que possam superar a barreira da comunicação, fazendo com que o surdo possa se apropriar do conhecimento transmitido em sala da aula. A Universidade de Washington organiza desde 2007 uma escola de verão visando aumentar o ingresso de alunos com deficiência nos cursos de Computação [Burgstahler et al., 2012], propondo a criação de parcerias entre escola-universidade, estágios em empresas e tutoria, para facilitar a transição e integração desses alunos na Universidade.

\section{O Surdo e a Ciência da Computação: relato de caso}

Esta seção traz relata atividades desenvolvidas por um aluno surdo ingressante no curso de Ciência de Computação em 2013. O aluno, fluente em Libras é proveniente de escola regular pública e ingressou na Universidade por meio de concurso vestibular. Além da surdez, o aluno apresenta dificuldade motora moderada. O curso passou a interagir com o Programa Institucional de Ações Relativas às Pessoas com Necessidades Especiais (PEE) para compreender como atuar com as especificidades desse aluno.

Nesses dois primeiros anos do curso, a grade conhecida pelo aluno foi apenas a do primeiro ano, que contem as seguintes disciplinas, todas em regime anual: Introdução à Ciência da Computação (68 horas-aula); Geometria Analítica e Álgebra Linear (136 horas-aula); Algoritmos (204 horas-aula); Física (136 horas-aula), Cálculo Diferencial e Integral (136 horas-aula) e Lógica e Matemática Discreta (102 horas-aula).

No ano letivo de 2013 o aluno foi acompanhado apenas por um TILS (nem sempre o mesmo), e não obteve aprovação em nenhuma disciplina. No ano de 2014, já sabido que a dificuldade motora, a não fluência em português escrito e a dinâmica de olhar para o TILS para compreender o conteúdo impediam o aluno de tomar notas para estudo posterior, um transcritor/ledor foi contratada pela instituição, via PEE, para acompanhá-lo, ficando responsável por copiar todos os conteúdos e explicações adicionais passados em sala de aula. Neste ano, o transcritor foi o mesmo em todas as disciplinas, enquanto que dois TILS atuaram de forma regular com o aluno. A alocação realizada pelo PEE evitou - mas nem sempre conseguiu - a alternância de TILS em uma mesma disciplina. Após praticamente dois bimestres, em reunião do PEE com a coordenação do curso, foi detectado que o aluno apresentava baixo rendimento, similar ao verificado em 2013. Como encaminhamento de solução, foi proposto então que o aluno reduzisse o número de disciplinas, que optou por continuar com Introdução à Ciência da Computação, Geometria e Álgebra Linear, Física e Lógica e Matemática Discreta. Essa solução foi adotada, pois em algumas aulas, principalmente ao final do dia, o aluno estava extremamente cansado e desmotivado. Apesar de transitória, essa solução surtiu efeito, já que das quatro disciplinas o aluno logrou aprovação em três.

As experiências das disciplinas Introdução em Ciência da Computação, Algoritmos, Geometria Analítica e Álgebra Linear e Física serão relatadas apresentando 
a visão dos docentes envolvidos, bem como a visão dos profissionais do PEE que acompanharam o aluno nesses dois anos. Cabe observar que os docentes não conheciam Libras e que foi a primeira oportunidade de atuação com um aluno surdo.

\subsection{Introdução à Ciência da Computação}

Ministrada por professor com mestrado e doutorado em Ciência da Computação, o objetivo desta disciplina é introduzir conceitos básicos da área, iniciando por histórico da computação, e após a representação binária, hexadecimal, octal e o armazenamento e operação de diferentes tipos de dados em computador, como números inteiros, ponto flutuante e texto, além dos conceitos básicos da organização de um computador e dos diferentes tipos de software. A última parte, mais informativa, traz professores de diferentes áreas da computação (em média, oito a cada ano) que apresentam palestras, tornando essa uma característica particular e desafiadora para o aluno e para a intérprete.

A disciplina é dividida em duas partes bem distintas, a primeira com uso intensivo de conceitos matemáticos da representação de números na base binária, decimal, hexadecimal e octal, que também inclui a representação de números sinalizados com o uso de padrões como sinal magnitude e complemento de dois, e operações matemáticas utilizando essas representações. Estes conceitos foram de fácil assimilação e não trouxeram maiores dificuldades, por serem passíveis de relacionar com os já adquiridos principalmente da Matemática. Foi adotado um símbolo para representar o conceito de complemento de dois, e para a representação do sinal magnitude foi utilizado o símbolo de sinal (positivo ou negativo), já conhecido pelo aluno. A segunda parte da disciplina é mais conceitual e envolve a definição de elementos de hardware e software. Nesta parte, houve maior dificuldade de compreensão pela intérprete e pelo aluno. Um universo novo de definições foi apresentado, e tanto a intérprete que não é da área quanto o aluno sentiram dificuldades. Adicionalmente, notou-se que o conjunto limitado de conceitos e o fato de o aluno não compreender o português dificultou o aprendizado.

A Computação também se apropria de analogias para criar termos relativos a tecnologias ou soluções. O próprio termo hardware e software é uma analogia entre a parte material e lógica dos componentes de um computador. Outro exemplo que causou confusão foi o termo computação em nuvem (do inglês Cloud Computing), apresentado em uma aula introdutória de novos modelos de computação, onde foi explicado que o termo nuvem se referia ao acesso de computadores localizados de forma remota e que o usuário não sabia necessariamente o local e a capacidade dos recursos disponíveis. A intérprete utilizou o sinal de nuvem mais computador para traduzir o termo para o aluno. Ao final da aula o aluno perguntou se computação em nuvem seriam os satélites armazenando dados de computadores. Detectado o erro de conceito, foi explicado que o termo nuvem não se refere à nuvem real e que serve apenas para dizer que o computador está distante do usuário, mas não no sentido físico da palavra.

Em termos metodológicos, não houve grandes alterações no planejamento da disciplina. Entre as alterações estão a maior utilização de exemplos de caráter visual e a realização de exercícios com correção em sala de aula. Para os documentários exibidos foi preparado um texto com a descrição dos temas abordados repassado antecipadamente à intérprete. Após a exibição, uma discussão era realizada sobre os pontos abordados, inclusive reapresentando algumas partes para melhor compreensão. 
Em relação às provas, devido a dificuldades motoras, o previsto em legislação que é $50 \%$ de tempo adicional, é insuficiente para o aluno. Dependendo do tema algumas adaptações foram realizadas. A prova que versava sobre bases numéricas e operações sobre dados foi reduzida em termos do número de exercícios ou mesmo o dado a ser calculado. Por exemplo, num exercício de mudança de base binária para decimal, um número binário de 4 bits foi utilizado na prova, reduzindo o número de operações necessárias para fazer a conversão. No entanto, essa redução não prejudica a avaliação, sendo possível verificar o nível de aprendizagem do aluno. Em outras partes, em que não é possível fazer este tipo de redução, optou-se por dividir a prova em duas partes, aplicando-a em dias distintos. Em relação aos trabalhos, uma adaptação foi realizada com as apresentações, de forma que com um conjunto de questões preparado, o aluno com a intermediação da intérprete defendia o trabalho realizado. Para facilitar a comunicação e verificação de conhecimento adquirido, um cuidado especial foi tomado na preparação das questões para que fossem objetivas e conseguissem avaliar o conhecimento adquirido, facilitando a comunicação professor-TILS-aluno.

O maior impacto foi a constatação de que o aluno não compreende textos em português e que todo o conhecimento adquirido é intermediado pela intérprete. Esse desafio se impôs principalmente em partes que necessitavam de conceituação ou mesmo analogias. Por outro lado, em conceitos relacionados à Matemática o aluno sempre teve bom desempenho, e em algumas ocasiões, superior aos alunos ouvintes. Por exemplo, quando apresentadas as propriedades de deslocamento de bits à esquerda que multiplica o número por $2^{\mathrm{n}}$, onde $N$ é o número de bits deslocados, foi perguntado à turma como seria possível a multiplicação de um dado número $M$ por 5 . $O$ aluno surdo foi o primeiro a apresentar a solução indicando o deslocamento à esquerda por dois bits (multiplicação por 4), e soma por mais $M$. Como todas as representações são matemáticas e os conceitos eram conhecidos, isto possibilitou que o aluno apresentasse a solução.

\subsection{Geometria Analítica e Álgebra Linear}

Ministrada por professora licenciada em Matemática com doutorado em Métodos Numéricos em Engenharia, visa proporcionar uma compreensão gradativa da caracterização da Álgebra Linear, começando com o estudo direcionado de vetores e de sistemas de equações lineares e matrizes, culminando com o estudo formal da estrutura do espaço vetorial e das transformações lineares.

A comunicação nas aulas e apoio didático não ocorreu de forma natural. Numa tentativa de amenizar esse problema de comunicação, a professora iniciou um curso introdutório de Libras. Não há, durante um ano letivo, tempo hábil para fluência nessa língua. Contudo, o curso foi fundamental para entender o tempo necessário para a intérprete fazer a tradução e compreender como o surdo se comunica.

O acadêmico fez esta disciplina duas vezes. No segundo ano a dificuldade de comunicação foi amenizada, revelando a importância de um conhecimento básico em Libras pelo docente. Houve a instrução dos TILS com relação à postura a frente da sala de aula, a exemplo de falar sempre de frente para o acadêmico e de forma pausada. Além disso, a prática de falar e escrever ao mesmo tempo foi abolida.

Observou-se o quanto a não formação na área pode influenciar a interpretação da aula. Como um primeiro exemplo, a intérprete não identificou a diferença na representação de uma matriz e do determinante de uma matriz e, ao interpretar para o acadêmico, não se atentou à distinção. Outro exemplo envolveu o sinal utilizado para 
ângulo. A intérprete não fez distinção entre o sinal utilizado para um ângulo qualquer e para o ângulo de $90^{\circ}$, um claro problema de comunicação. $\mathrm{O}$ que mais preocupa são as inúmeras situações em que isso pode ter ocorrido sem que a professora se atentasse ao fato, já que a não compreensão de Libras dificulta a identificação de tais situações. As situações vivenciadas só foram detectadas pelo acadêmico. A intérprete, pela não formação na área, não sabia do seu equívoco, enquanto a professora, sem saber Libras, não conseguia identificá-las.

Sobre os problemas de conceituação do acadêmico, alguns foram observados na disciplina. $\mathrm{Na}$ definição de vetor, por exemplo, houve dificuldades para explicar a diferença entre sentido e direção. Quanto aos sinais, vários precisaram ser criados (ou combinados) com o acadêmico: vetor, matriz, Transformação Linear, entre outros.

As provas da disciplina sofreram mudanças em relação ao número de questões e em relação ao "tamanho" das questões. Como no primeiro ano em que o acadêmico fez a disciplina estas mudanças não ocorreram, foi possível perceber que o fato de não responder as questões completamente estava relacionado ao tamanho. $\mathrm{O}$ acadêmico resolvia somente os primeiros questionamentos, não completando a questão. Com a mudança, este problema foi resolvido. A adaptação no número de questões foi necessária para que o aluno tivesse disposição para resolver toda a prova. O tempo para resolução da prova sempre foi maior e, na maioria das vezes, em ambiente diferente.

Enfim, são necessárias mudanças de práticas pedagógicas antigas, o que não é fácil nem rápido. Uma postura difícil, por exemplo, o formalismo, que teve que ser deixado de lado várias vezes, para se fazer compreender pela intérprete e pelo aluno surdo. Para resolver desses alguns problemas, a ajuda foi mútua entre docente e TILS, embora quase todos sem nenhuma experiência.

\subsection{Algoritmos}

Ministrada professor com mestrado e doutorado em Ciência da Computação, mas ministrando-a pela primeira vez, o objetivo desta disciplina é o estudo das formas de representação do pensamento lógico por meio de técnicas de desenvolvimento de algoritmos e da representação e manipulação de dados na memória de um computador.

A disciplina é dividida em aulas teórica e práticas. As aulas teóricas foram ministradas em uma sala comum, com o uso de quadro-negro ou projetor multimídia. Durante essas aulas, os principais conceitos e exemplos eram apresentados visualmente, usando os recursos disponíveis, e explicados de modo oral na sequência. Quando solicitado pela intérprete, interrompia-se a aula e sanavam-se as dúvidas dela própria e do aluno. Muitas vezes era necessário retomar o mesmo assunto, buscando encontrar uma forma mais facilmente compreendida pela intérprete. Também foram disponibilizados alguns materiais adicionais para que o TILS e transcritor pudessem se familiarizar com os termos usados na disciplina. As aulas práticas eram realizadas em laboratório e consistiam na implementação de algoritmos no computador. Os enunciados eram explicados à intérprete que tratava de traduzir e repassá-los ao aluno.

Durante essas atividades práticas foram notadas as principais dificuldades do aluno. A primeira delas consistia em compreender os enunciados dos problemas e convertê-los para a linguagem algorítmica, mesmo com o auxílio da intérprete. Muitos conceitos utilizados nos enunciados não eram passíveis de uma tradução direta usando Libras, e considerando que o aluno não era fluente em português, se faziam necessárias adaptações na tradução, o que causava problemas de interpretação. Tais problemas eram 
menos significativos em exercícios mais simples, onde não havia a necessidade de maior nível de interpretação. Já os enunciados que continham mais elementos interpretativos, bastante comuns em algoritmos, eram raramente resolvidos pelo aluno.

Há que considerar também a dificuldade motora do aluno, que causava problemas tanto na velocidade quanto na qualidade da digitação do código-fonte. Sabese que na programação de computadores os comandos devem ser digitados de modo exato ou causarão erros durante a compilação/interpretação do código. A dificuldade de entender a língua portuguesa também influenciava negativamente na sua capacidade de entender mensagens de erro emitidas pelo ambiente de programação, que também geralmente não eram compreendidas pelas intérpretes. Assim, para a compreensão dos erros e a correção dos programas exigia-se a participação do professor, que muitas vezes não podia atender rapidamente pelo auxílio os demais alunos da turma.

As dificuldades de compreensão e em construir um programa funcional causavam cansaço e irritação ao aluno, sendo necessária a intervenção da intérprete e do professor para motivá-lo a continuar as atividades de laboratório e finalizá-las em outros horários. Após quatro meses, o aluno resolveu deixar a disciplina para ser cursada nos anos subsequentes, inclusive por indicação da coordenação do curso e do PEE.

\subsection{Física}

Ministrada por professor com mais de dez anos de atuação com este conteúdo, a disciplina de Física envolve conteúdos de eletricidade básica, com ênfase na análise de circuitos de corrente contínua.

Logo após as primeiras aulas em março de 2013, o TILS relatou ao docente que a falta do conhecimento específico da área afetaria suas escolhas lexicais, uma vez que esta escolha é importantíssima quando não há o sinal existente nas diversas áreas de interpretação. No decorrer das aulas, mesmo não dominando os significados de alguns conceitos, o TILS e o acadêmico criaram sinais para facilitar a interpretação e a compreensão do conteúdo. Porém, na primeira avaliação ficou claro que tal procedimento não gerou bons resultados, pois transparecia nas respostas do acadêmico que este estava confundindo conceitos, o que chamou a atenção do docente à atuação do TILS. Após algumas observações e, apesar de desconhecer a Libras, o professor detectou que o TILS estava utilizando um mesmo sinal para terminologias totalmente distintas, o que poderia ser a causa da distorção dos conceitos. Por exemplo, utilizava do mesmo recurso linguístico (sinal) para identificar os termos energia, eletricidade, carga elétrica, circuito elétrico, corrente e tensão elétrica. Diante disso, o professor realizou encontros específicos com o TILS e o aluno, a fim de esclarecer diferenças conceituais e contribuir para a adequação dos sinais utilizados. Para tanto, o professor lançou mão de recursos didáticos adicionais, como a intensificação da utilização de recursos visuais, seja por meio de diagramas ou desenhos e demonstrando o conceito de forma aplicada ao cotidiano. Um exemplo foi a criação do sinal que identifica o resistor, gerado durante o contato do TILS e do aluno com o dispositivo físico no laboratório.

No ano de 2014 o aluno esteve novamente matriculado, e professor e intérprete traçaram diferentes estratégias para avaliação da evolução do aluno, com horários adicionais para discussão das dúvidas e listas de exercícios diferenciadas. De fato, este tipo de estratégia de maior proximidade ao aluno surtiu efeito, revelado na avaliação escrita onde o aluno surdo demonstrou não somente domínio sobre métodos de 
resolução de problemas, mas o domínio conceitual necessário à interpretação dos problemas propostos, obtendo conceito suficiente para aprovação.

\subsection{A Visão do PEE}

Os profissionais do PEE relataram duas dificuldades adicionais em seu trabalho: (i) dado que a Libras não apresenta um glossário compatível com o português alguns sinais tiveram que ser adequados. (ii) a não existência de sinais da Libras específicos da área de Ciência da computação e para algumas terminologias em inglês.

Neste contexto, a interação TILS e docentes foi fundamental. Segundo esses profissionais: "O atendimento que os docentes disponibilizam ao acadêmico é muito importante, visto que ele é atendido individualmente no apoio didático, e estes nunca se negaram ou colocaram qualquer empecilho ao atendimento do aluno. Nas avaliações, respeitam o tempo adicional necessário para sua realização, e são sempre atenciosos para sanar dúvidas, sejam elas do acadêmico, do Tradutor/interprete de Libras ou do Transcritor/ledor, pois algumas vezes os profissionais de apoio também necessitam de atendimento do docente, para poderem fazer a explanação de conceitos, ou até mesmo, de sinônimos para os termos técnicos do Curso. A coordenação foi muito compreensiva no momento que o PEE o orientou a necessidade de diminuir a carga horária das disciplinas no decorrer do ano letivo, apoiando e justificando essa necessidade nas questões burocráticas, como também agilizando o contato entre os docentes e a equipe do PEE que acompanha o aluno.".

\section{Conclusões}

A avaliação da evolução da aprendizagem de alunos surdos é uma tarefa ainda mais complexa que a de alunos ouvintes, principalmente para professores que não foram devidamente preparados para atuar com estes alunos. A avaliação do conhecimento construído pelos alunos surdos não deve ser pautada pela avaliação de alunos ouvintes, possuindo aspectos diferenciados que devem ser considerados. Devido à particularidade da comunicação mediada, a avaliação do aluno surdo deve ocorrer continuamente e contar com o auxílio do TILS que atua em sala de aula acompanhando o processo de ensino-aprendizagem, levando em conta que a língua materna do aluno é a Libras.

Uma dificuldade encontrada é a impossibilidade de aferir se um determinado conceito foi corretamente assimilado pelo aluno. Verificou-se durante o apoio didático, realizado em horário extraclasse, que alguns conceitos anteriores deveriam ser trabalhados ou mesmo apresentados ao aluno. Considerando que a intérprete não apresenta formação na área e que o professor não conhece Libras, não é possível verificar se o conceito foi passado de modo correto para o aluno durante o processo de tradução. A relação entre estes atores no processo de ensino-aprendizagem pode ser assim resumida: professor e aluno detêm conhecimento, avançado e básico, respectivamente, sobre o conteúdo trabalhado, porém não compartilham a Libras; TILS e aluno compartilham Libras, mas não o conhecimento básico; professor e TILS compartilham língua portuguesa, mas não o conhecimento específico.

Um ponto para discussão constatado nessa experiência é que o professor deve contar com o apoio do intérprete na correção das provas escritas, uma vez que esse profissional, habilitado e proficiente em Libras pode auxiliar na compreensão da estrutura e dos sentidos dos textos produzidos pelo aluno surdo. 
A comunicação é o maior limitante. Hoje, um curso básico de Libras já é obrigatório em cursos de licenciatura, mas não é suficiente, pois é preciso formar para a inclusão. Alguns autores questionam a ideia de que a simples presença do TILS em sala de aula garanta acessibilidade aos estudantes surdos comparável à dos ouvintes, mesmo em situações ideais, em que o preparo dos intérpretes seja excelente [Bisol, 2010]. Metodologias adequadas, disponibilização de recursos, assistência pedagógica e psicológica devem ser conhecidas e estar à disposição para uma efetiva inclusão. Este foi o caminho adotado, no qual a transcritor/ledor foi inserido, e fundamental para que o aluno desenvolvesse as atividades extraclasses e se apropriasse do conhecimento.

Para um ganho multifacetado, é necessária a colaboração efetiva entre os três atores do processo (professor, TILS e aluno), sem a qual os resultados são incompletos. No caso específico, o aluno mostrou interesse e disposição, comparecendo às atividades programadas extraclasses. Os intérpretes também tiveram grande envolvimento, sendo motivados a ingressar em cursos de pós-graduação stricto sensu, pesquisando assuntos relacionados aos problemas enfrentados em sala de aula. No caso dos docentes, a experiência permitiu rever estratégias de ensino e o aprimoramento do processo de avaliação extensível a todos os alunos da turma, além de despertar interesse de investigação científica nessa área ainda carente de estudos aprofundados.

As principais preocupações de professores e TILS com o uso de Libras no ensino inclusivo de disciplinas envolvendo a subáreas das Ciências Exatas são: conhecida a falta de sinais específicos para Libras, quais os problemas relacionados ao uso de Libras nas aulas? Qual o real papel do TILS na transmissão da informação? Como a interação professor-TILS-aluno pode contribuir no processo de ensino-aprendizagem?

Os resultados dessa experiência podem ser analisados de forma tripartida: 1) os professores ganharam experiência que vai além da formação inicial ou área de atuação; 2) TILS foram treinados para lidar com situações que ultrapassam a interpretação de sinais já existentes, atuando na criação de sinais específicos que enriquecem o portfólio de sinais que pode ser usado em outras disciplinas ou em outros cenários de interpretação; e, 3) o aluno além de se apropriar do conhecimento, participou da criação de sinais e da construção de significados que poderão ser incorporados à sua língua.

Dentre as lições aprendidas, destacam-se: a necessidade de cada professor conhecer a surdez e como se dá o processo de aquisição de conhecimento, realizando reuniões no início do ano e periódica entre os professores que atuam com o aluno surdo; a utilização de metodologias adequadas com ênfase em aspectos visuais; a revisão do processo de avaliação para que seja possível mesurar o conhecimento com vistas às limitações; a contínua comunicação entre professor-TILS-aluno para verificar ambiguidades e erros inseridos no processo de tradução.

Este relato permite observar a evolução do acadêmico surdo e mostra que as diversas estratégias metodológicas e de assistência pedagógica adotadas foram importantes para garantir essa evolução. Mesmo com tantas dificuldades no processo de ensino-aprendizagem, é preciso garantir, como dever institucional, que o aluno evolua. Enfim, é preciso que a universidade esteja preparada para receber alunos surdos, oferecendo assistência pedagógica e especializada (monitorias ou tutorias) ao acadêmico. Também é preciso que uma assessoria pedagógica seja criada para auxiliar e discutir com os professores diferentes formas para garantir a efetiva inclusão ou até mesmo adaptações em termos de disciplinas cursadas, para que o aluno conclua o curso a seu próprio tempo e de acordo com as suas possibilidades. 
Essa pesquisa continua, portanto, com os vários desafios supra relatados. Outra proposta de trabalho é a análise da sua integração com alunos ouvintes, averiguando sua opinião e como poderiam ajudar no processo de ensino-aprendizagem do aluno surdo.

\section{Referências}

ANDREI, S., OSBORNE, L.; SMITH, Z. (2013). Designing an American Sign Language Avatar for Learning Computer Science Concepts for Deaf or Hard-ofHearing Students and Deaf Interpreters. Journal of Educational Multimedia and Hypermedia. 22 (3), pp. 229-242.

BISOL, C. A.; VALENTINI, C. B.; SIMIONI, J. L.; ZANCHIN, J. (2010) Estudantes surdos no ensino superior: reflexões sobre a inclusão. In: Cadernos de Pesquisa, v.40, n.139, p. 147-172.

BOTAN, E.; CARDOSO, F. C. (2008) A Física, a Língua Brasileira de Sinais e a divulgação científica: a imobilidade da cinemática no ensino de Física. In: Seminário Educação 2008, Cuiabá/ MT. Trabalhos de 2008. Cuiabá: UFMT.

BURGSTAHLER, S.; RADNER, R.E.; BELLMAN, S. (2012) Strategies for increasing the participation in computing of students with disabilities. In: ACM Inroads, v. 3, n. 4, p. 42-48, dezembro 2012.

CRUZ, J. I. G.; DIAS, T. R. S (2009). Trajetória escolar do surdo no ensino superior: condições e possibilidades. Revista Brasileira de Educação Especial, v.15, n.1, p.6580, jan-abr. 2009.

DAROQUE, S. C. (2011) Alunos surdos no ensino superior: uma discussão necessária. Dissertação de Mestrado- Programa de Pós-Graduação em Educação, Faculdade Metodista, Piracicaba, SP.

FERNANDES, S. (2008) Letramentos na educação bilíngue para surdos: caminhos para prática pedagógica. In: IV Simpósio Internacional sobre Práticas Escritas na Escola. São Paulo: Departamento de Letras Clássicas e Vernáculas.

LEITE, E. M. C. (2004) Os papéis do intérprete de Libras na sala de aula inclusiva. Petrópolis, Arara Azul.

MOREIRA, FERNANDES (2008) Acesso e permanência de estudantes surdos no ensino superior. In: I SIES Seminário sobre Inclusão no Ensino Superior, 2008, Londrina - PR. Palestra. Londrina: UEL.

PAGNEZ, K. S.; SOFIATO C. G. (2014) O estado da arte de pesquisas sobre a educação de surdos no Brasil de 2007 a 2011, Educar em Revista, n.52, p. 229-256.

QUADROS, R. M. (2004) O tradutor e intérprete de língua brasileira de sinais e língua português, Secretaria de Educação Especial; Programa Nacional de Apoio à Educação de Surdos, Brasília:MEC;SEESP.

QUADROS, R. M.; KARNOPP, L. (2004) Língua Brasileira de Sinais: Estudos Linguísticos, Porto Alegre: Artes Médicas.

RAMOS, D. M.; ZANIOLO, L. O. (2014) Tendências e Perspectivas da Produção Acadêmica sobre a Temática Educação de Surdos: Mapeamento da Produção, Rev. Bras. Ed. Esp., v. 20, n. 2, p. 303-318.

SILVA, J. F. C. (2013) O ensino de Física com as mãos: Libras, bilinguismo e inclusão, Dissertação de Mestrado - Programa de Pós-Graduação Interunidades em Ensino de Ciências, USP, São Paulo, SP. 